\title{
THE LEUVEN EXPERIENCE WITH A DICHOTOMY IN BRONCHIOLITIS OBLITERANS SYNDROME (BOS) AFTER LUNG TRANSPLANTATION REVEALED BY AZITHROMYCIN
}

\author{
Bart Vanaudenaerde*, Robin Vos*, Nele Geudens”, Dirk Van Raemdonck\#, Lieven Dupont* and Geert Verleden* \\ Lung Transplantation Best Abstract Award, sponsored by Roche Pharma AG \\ *Laboratory of Pneumology, KULeuven, Leuven, Belgium \\ \#Laboratory of Experimental Thoracic Surgery, KULeuven, Leuven, Belgium
}

WINNING ABSTRACT: BOS is the most important cause of late mortality after LTx. Until 5 years ago, the prevalence was around $30 \%$ and $50 \%, 3$ and 5 years after LTx. Introduction of azithromycin (AZI) improved the FEV 1 in $40 \%$ of BOS patients. AZI treatment may explain why in our center, the BOS prevalence at 3 years has decreased from $30 \%$ to $15 \%$ compared to the ISHLT registry. Opposed to the current belief about BOS, we hypothesize a dichotomy within BOS: Neutrophilic Reversible Allograft Dysfunction (NRAD) and fibropoliferative BOS (fBOS; table 1). This dichotomy is based on the discrepancy in AZI response and observations within our center consisting of clinical, biochemical and cellular (BAL) analysis.

NRAD makes a re-evaluation of the BOS definition (irreversible FEV 1 decline, neutrophilic inflammation, fibroproliferation) indispensable. As it is reversible, NRAD should be excluded from BOS and accepted as innate (non-specific) inflammation and as an important risk factor for the development of BOS. So after exclusion of other complications such as acute rejection, infection, gastro-oesophageal reflux and after a trial with AZI, BOS will remain what it is now (the fBOS). This implements a reevaluation of the neutrophilic inflammation, as it is a prerequisite for AZI responsiveness. BOS can then histologically be characterized as pure inactive $\mathrm{OB}$, which is hardly responsive to any treatment.

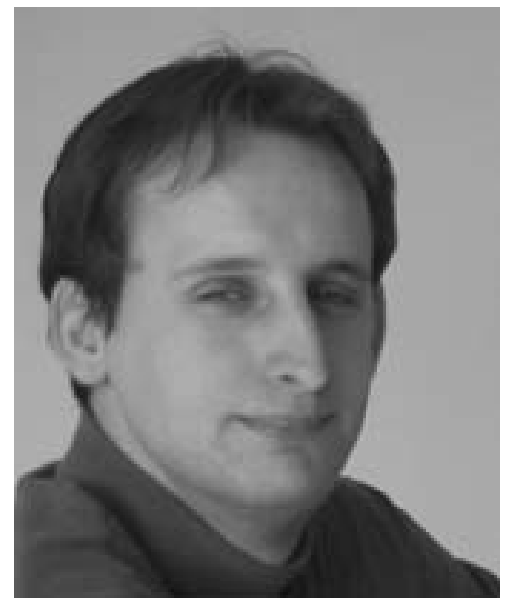

Bart Vanaudenaerde

Laboratory of Pneumology and Lung Transplant Unit, Leuven, Belgium

\section{SYNOPSIS OF MY JOB AND THE ROLE OF THE UNIT IN WHICH I WORK}

I work in the Laboratory of Pneumology at the Katholieke Universiteit (Leuven, Belgium). Within the laboratory, research focuses on: chronic obstructive pulmonary disease (involvement of inflammatory and systemic mechanism); pulmonary hypertension (the role of the endothelium), interstitial lung disease (the involvement of innate inflammation); lung toxicology (mouse models of chemical-induced asthma,

STATEMENT OF INTEREST: During his PhD, B. Vanaudenaerde received funding from the research foundation Vlaanderen (Belgium; grant no. G.0493.04) epidemiological research on cadmium and air pollution, and in vitro research on particulate matter and nanoparticles); and lung transplantation (inflammatory mechanisms in bronchiolitis obliterans syndrome (BOS)). In 2001, under the guidance of Professor Geert M. Verleden, we started experimental research on lung transplantation in our laboratory.

While writing this report, we are awaiting the 400th lung transplantation in our centre. During the last few years, $\sim 40$ lung transplantations have been performed each year, 2006 was the best-ever year, with 57 procedures carried out (fig. 1). As a result, our centre has extensive clinical experience (the programme started in 1991), both in the selection and followup of these patients, which is performed in the University Hospital Gasthuisberg (Leuven, Belgium).

Translational research is our philosophy in investigating BOS in our centre. The clinical programme is supervised by Professor G.M. Verleden and Professor L.J. Dupont. Under their guidance, and together with Dr Wim Wuyts and Dr Robin Vos, I manage the experimental section of the lung transplantation research, specifically the inflammatory mechanisms involved in acute and chronic rejection. It is with this philosophy of translational research that we were able to contribute to the understanding of BOS more specifically, by exploring the involvement of interleukin (IL)-17, IL-8 and neutrophils in combination with the possible modulatory effect of azithromycin.

\section{SYNOPSIS OF MY RESEARCH AND HOW MY WINNING POSTER IS PART OF THIS}

My PhD thesis is entitled "Bronchiolitis Obliterans Syndrome after azithromycin and beyond: from clinical experience to basic science and back" and was finalised in May 2007. An in vitro experiment with primary human airway smooth muscle 


\begin{tabular}{lcc} 
TABLE 1 A hyphothesised dichotomy & NRAD & No neutrophils \\
& Neutrophils & No crackles, little sputum \\
\hline Airway inflammation & Late \\
$\begin{array}{l}\text { Clinical picture } \\
\text { Time after transplantation }\end{array}$ & Crackles, increased sputum production & Fast, 6 months \\
$\begin{array}{l}\text { Course } \\
\text { Histology }\end{array}$ & Slowly, several years & Merely fibrotic \\
AZl therapy & Initially inflammation, finally fibrosis & Not beneficial/irreversible \\
\hline
\end{tabular}

NRAD: neutrophilic reversible allograft dysfunction; fBOS: fibropoliferative bronchiolitis obliterans syndrome; AZl: azithromycin.

cells to explore the potential role of IL-17 in the development of BOS was the starting point of my research [1]. This study led to a grant from the research foundation Vlaanderen (Belgium), making it possible to further explore the mechanism of BOS in vitro with the involvement of IL-8 chemokine and oxidative stress production through the mitogen-activated kinase intracellular pathway $[2,3]$. Additionally, we installed a routine follow-up of our lung transplant patients with bronchoscopy and bronchoalveolar lavage (BAL). Analysis of the BAL fluid confirmed the involvement of IL-17 in patients who developed acute rejection or BOS [4,5]. A study by GERHARDT et al. [6] has demonstrated, for the first time, a reversal of the disease by macrolides, especially azithromycin; we also focused our attention on the mechanisms of azithromycin. We demonstrated both in vitro and in patients with BOS that innate immunity with IL-8 and neutrophils are key elements to explaining the mechanism of action of azithromycin [7-10]. This led us to speculate about a dichotomy in the development of BOS based on the response to azithromycin therapy, as I presented at the 2007 European Respiratory Society Congress in my winning abstract.

\section{HOW MY RESEARCH FITS INTO THE OVERALL RESEARCH OF MY WORKING GROUP/RESEARCH TEAM}

As we demonstrated neutrophilic inflammation to be a key element in explaining the response to azithromycin, our group focused on several topics that are able to induce this

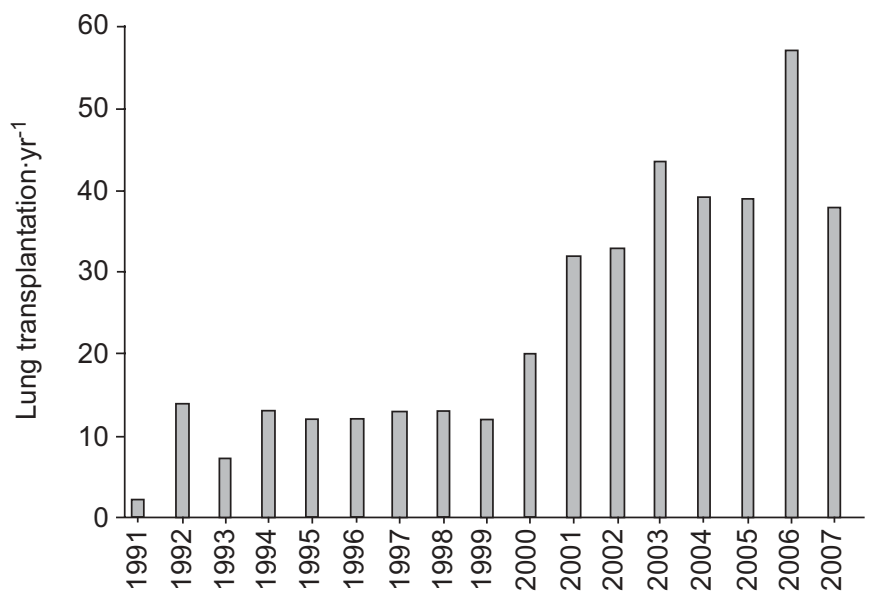

FIGURE 1. The number of lung and heart-lung transplantations performed at the University Hospital Gasthuisberg (Leuven, Belgium) from 1991-2007. neutrophilia. We confirmed that pseudomonal colonisation and bile acid reflux are involved [11-13]. A placebo-controlled, double-blind randomised clinical trial with azithromycin is currently being carried out in 75 patients, which aims to demonstrate a decrease in the prevalence of BOS at 2 and 3 yrs after transplantation.

\section{HOW MY RESEARCH WILL IMPACT ON CLINICAL OR RESEARCH PRACTICE}

At the end of these experiments, we focused our attention on this dichotomy within bronchiolitis obliterans syndrome. It is surprising to see that the combination of clinical and experimental research has led to a better understanding of the pathophysiological mechanisms of bronchiolitis obliterans syndrome and also to the start of bronchiolitis obliterans syndrome phenotyping. Questions have also arisen concerning the definition of bronchiolitis obliterans syndrome, which probably needs further refinement. Thus, a working group, led by Professor G.M. Verleden, is being formed by the International Society for Heart and Lung Transplantation pulmonary council to revise bronchiolitis obliterans syndrome. This may ultimately lead to better management of the lung transplant patient.

\section{REFERENCES}

1 Vanaudenaerde BM, Wuyts WA, Dupont LJ, Van Raemdonck DE, Demedts MM, Verleden GM. Interleukin17 stimulates release of interleukin- 8 by human airway smooth muscle cells in vitro: a potential role for interleukin17 and airway smooth muscle cells in bronchiolitis obliterans syndrome. J Heart Lung Transplant 2003; 22: 1280-1283.

2 Wuyts WA, Vanaudenaerde BM, Dupont LJ, Van Raemdonck DE, Demedts MG, Verleden GM. Interleukin17-induced interleukin-8 release in human airway smooth muscle cells: role for mitogen-activated kinases and nuclear factor-кB. J Heart Lung Transplant 2005; 24: 875-881.

3 Wuyts WA, Vanaudenaerde BM, Dupont LJ, Van Raemdonck DE, Demedts MG, Verleden GM. N-acetylcysteine inhibits interleukin-17-induced interleukin-8 production from human airway smooth muscle cells: a possible role for anti-oxidative treatment in chronic lung rejection? J Heart Lung Transplant 2004; 23: 122-127.

4 Vanaudenaerde BM, Dupont LJ, Wuyts WA, et al. The role of interleukin-17 during acute rejection after lung transplantation. Eur Respir J 2006; 27: 779-787.

5 Vanaudenaerde BM, Dupont LL, Wuyts WA, Seghers S, Van Raemdonck DE, Verleden GM. IL8 and IL17 are upregulated 
in BAL fluid of lung tranplant patients with bronchiolis obliterans syndrome. Eur Respir J 2004; 24: Suppl. 48, 465s.

6 Gerhardt SG, McDyer JF, Girgis RE, Conte JV, Yang SC, Orens JB. Maintenance azithromycin therapy for bronchiolitis obliterans syndrome: results of a pilot study. Am J Respir Crit Care Med 2003; 168: 121-125.

7 Verleden GM, Dupont LJ. Azithromycin therapy for patients with bronchiolitis obliterans syndrome after lung transplantation. Transplantation 2004; 77: 1465-1467.

8 Verleden GM, Dupont LJ, Van Raemdonck DE. Is it bronchiolitis obliterans syndrome or is it chronic rejection: a reappraisal? Eur Respir J 2005; 25: 221-224.

9 Verleden GM, Vanaudenaerde BM, Dupont LJ, Van Raemdonck DE. Azithromycin reduces airway neutrophilia and IL-8 in patients with bronchiolitis obliterans syndrome. Am J Respir Crit Care Med 2006; 174: 566-570.
10 Vanaudenaerde BM, Wuyts WA, Geudens N, et al. Macrolides inhibit IL17-induced IL8 and 8-isoprostane release from human airway smooth muscle cells. Am J Transplant 2007; 7: 76-81.

11 Vos R, Vanaudenaerde BM, Dupont LJ, Van Raemdonck DE, Verleden GM. Transient airway colonization is associated with airway inflammation after lung transplantation. Am J Transplant 2007; 7: 1278-1287.

12 Vos R, Vanaudenaerde BM, Geudens N, Dupont LJ, Van Raemdonck DE, Verleden GM. Pseudomonal airway colonisation: a risk factor for BOS after lung transplantation? Eur Respir J 2008 [Epub ahead of print PMID: 18256072].

13 Blondeau K, Mertens V, Vanaudenaerde BA, et al. Gastrooesophageal reflux and gastric aspiration in lung transplant patients with or without chronic rejection. Eur Respir J 2007; 31: 707-713. 